\title{
Text-Based Collaborative Work and Innovation: Effects of Communication Media Affordances on Divergent and Convergent Thinking in Group-Based Problem-Solving
}

\author{
Leif Jarle Gressgård \\ International Research Institute of Stavanger, Bergen, Norway \\ lig@iris.no
}

\begin{abstract}
This experimental study explores the relationship between text-based computer-mediated communication and innovative thinking in problem-solving groups. The research objective is to investigate how various levels of synchronicity, parallelism, and identification influence the divergent and convergent focus of the group members. An experiment involving group-based problemsolving by use of text-based communication tools was conducted. Manipulation of the communication tools ensured variation in the participants' perceptions of synchronicity, parallelism, and identification. The results of the experiment revealed few overall differences between the communication affordances on their effects on innovative thinking processes, implying that neither the divergent nor the convergent focus of the participants was influenced by different levels of synchronicity, parallelism, and identification. However, a significant effect between synchronicity and convergent focus opposite to the hypothesized direction was found. This suggests that low synchronous interaction may enhance convergent thinking for individuals with low preferences for evaluation.
\end{abstract}

Keywords: Computer-mediated communication, media affordances, innovative thinking, divergence, convergence, synchronicity, parallelism, identification.

\section{Introduction}

Computer-mediated communication (CMC) is increasingly being used to support collaborative work in a variety of organizational settings (Kuo \& Yu, 2009). An example of this is the frequent occurrence of virtual groups involved with new product development and innovation (de Leede, Kraan, den Hengst, \& van Hooff, 2008; Malhotra, Majchrzak, Carman, \& Lott, 2001). In order to generate new knowledge of desirable use of CMC in innovative group work, it is important to investigate how the distinctive characteristics of different communication media influence group

Material published as part of this publication, either on-line or in print, is copyrighted by the Informing Science Institute. Permission to make digital or paper copy of part or all of these works for personal or classroom use is granted without fee provided that the copies are not made or distributed for profit or commercial advantage AND that copies 1) bear this notice in full and 2) give the full citation on the first page. It is permissible to abstract these works so long as credit is given. To copy in all other cases or to republish or to post on a server or to redistribute to lists requires specific permission and payment of a fee. Contact Publisher@InformingScience.org to request redistribution permission. dynamics and innovative thinking processes.

Studies focusing on innovative work in groups communicating by use of electronic media generally apply different quality measures (e.g., number of ideas generated, average quality of ideas, and total quality produced) as outcome variables (Girotra, Terwiesch, \& Ulrich, 2010; Reinig, Briggs, \& Nunamaker, 
2007). Little emphasis has been put on how properties of CMC influence innovative thinking processes which in turn may impact on performance outcomes. This research applies such a process perspective, and the main objective of the study is to investigate how electronic communication media influence innovative thinking.

There are many theories focusing on the underlying features of CMC. Theories like the Media Richness Theory (Daft \& Lengel, 1986), Media Synchronicity Theory (Dennis, Fuller, \& Valacich, 2008; Dennis \& Valacich, 1999) and Burgoon et al.'s (1999) interactivity model all attempt to describe the constituent parts of mediated communication. Drawing on existing theoretical contributions, this study focuses on the effects of three communication affordances (synchronicity, parallelism, and identification) on divergent and convergent thinking processes in computer-mediated problem-solving in groups in a text-based collaboration environment.

The paper is organized as follows. First, the theoretical basis for the research is presented, followed by development of the hypotheses. The methodological approach is thereafter described, and the results of the hypotheses tests are presented. The paper concludes with a discussion of the results, study limitations and directions for future research.

\section{Theoretical Background}

\section{Communication Affordances}

Many theories have been developed to categorize media qualities and explain effects on communication processes and outcomes. One of the most widely used theories in this respect is the $\mathrm{Me}$ dia Richness Theory (MRT) (Daft \& Lengel, 1986), which posits that task performance will be improved when task information needs (i.e., the need for reduction of uncertainty and creation of a shared understanding) are matched to a medium's capacity for processing rich information. Daft and Lengel (1986) define information richness as "the ability of information to change understanding within a time interval" (p. 560), and the capacities of communication media to process rich information vary owing to differences in their abilities to provide rapid feedback, carry multiple cues, convey personality traits, and support language variety (Kock, 2005). Empirical tests involving new communication media have not been very supportive of MRT, however (see e.g., Burke \& Chidambaram, 1999). A particular weakness of the theory is that "richness" is perceived as an intrinsic and unalterable property of communication media. Yet media are not monolithic, and media richness is thus not invariant (Dennis et al., 2008).

Recognizing the weaknesses of MRT, Media Synchronicity Theory (MST) focuses on the abilities of media to support the communication processes of group work (Dennis et al., 2008; Dennis \& Valacich, 1999). MST identifies five capabilities of media (transmission velocity, symbol sets, parallelism, rehearsability, and reprocessability) that are important for understanding the effects of media use on the ability to communicate and process information. The theory suggests that these capabilities influence the development of "synchronicity", referring to the extent to which individuals are able to work together at the same time with a shared pattern of coordinated behavior (Dennis, Fuller, \& Valacich, 2009). MST further proposes that communication consists of the processes of conveyance of information and convergence on meaning, and that the preferred level of synchronicity depends on the process to be carried out. According to Dennis et al. (2008, 2009), media supporting lower synchronicity should result in better communication performance for conveyance of information, whereas high synchronicity should promote convergence on meaning.

Several studies have provided support for MST (e.g., DeLuca \& Valacich, 2006; Niinimäki, Piri, Lassenius, \& Paasivaara, 2011). There are also recent studies, however, which do not support the theory. For example, contrary to what is suggested by MST, Muhren, Van Den Eede, and Van de 
Walle (2009) found that low synchronicity is not sufficient to support conveyance of information. Further, the relationship between high synchronicity and convergence on meaning is also questioned. In their study of the use of an instant messaging system in four organizations, Hung, Duyen, Kong, and Chua (2008) found that the system was not as effective for convergence as it was for conveyance, even though it was perceived to be a highly synchronous communication medium.

In relation to the media capabilities emphasized by MST, Burgoon et al. (1999) suggest that communication media can be described and evaluated by their abilities to enable specific affordances of the communication process. These affordances partly correspond to the capabilities defined in MST, and in this respect Burgoon et al. (1999) argue that synchronicity, identification, and parallelism are among the important affordances that to various degrees are enabled by communication media. In their conceptualization, synchronicity refers to "whether the interaction is same-time, which permits immediate bidirectional feedback, or asynchronous, which permits rehearsability and editability", identification refers to "the extent to which participants are fully identified, partially identified, or anonymous", and parallelism refers to "whether the format permits concurrent communication and multiple addressees, as in the case of electronic brainstorming, or only permits serial messages" (p. 36).

As situational factors determine which affordances must be present (or are preferable), users are likely to perceive the usefulness of different media in the light of the tasks that are to be solved (Dennis, Wixom, \& Vandenberg, 2001). In this study, affordances which may influence divergent and convergent thinking processes in group-based problem-solving are emphasized. As will be argued in the hypotheses section, the affordances of synchronicity, parallelism, and identification are in this respect important.

On basis of the theoretical perspectives discussed above, the concept of synchronicity in this study refers to whether the interaction is same-time or not (Burgoon et al., 1999). The concept thus encompasses the capabilities called "transmission velocity" in MST and "feedback rapidness" in MRT, and is defined as "the extent to which the participants engaged in group-based problem solving can give immediate feedback to the postings of other group members, and receive immediate feedback on their own postings from other group members." This understanding of the concept is thus not equal to synchronicity as understood in MST and is also distinct from the concept of simultaneity (the message is produced and received at the same time) (Guo, Tan, \& Cheung, 2010).

Parallelism is defined as "the participants' opportunities to be engaged in simultaneous dialogues", and thus refers to the group members' opportunities to make contributions at any time without interrupting other group members. This is related to Burgoon et al.'s (1999) and Dennis and Valacich's (1999) definition of the concept (the number of simultaneous conversations that can effectively take place). High parallelism thus implies that the participants do not have to take turns in utterance of contributions, but can express their views as they occur. Low parallelism, on the other hand, means that all participants have to be engaged in a single conversation/discussion, implying that only one member of the group should utter his/her ideas and comments at a time.

In this respect, there may be situations where multithreading features of the media enable the participants to express their ideas simultaneously (in multiple dialogues) in spite of turn-taking rules or etiquette for each single thread. In these cases, the parallelism will be high as the communication media effectively enable multiple dialogues to occur at the same time (without interrupting other participants). Further, this conceptualization of synchronicity and parallelism requires a comment regarding their interrelatedness. That is, although these affordances refer to distinct characteristics of communication processes, they are not totally unrelated. Turn-taking in order to avoid interruption is crucial for low parallelism, and this is more relevant when the level of syn- 
chronicity is high. As a consequence of time-lags between contributions which occur in low synchronous interaction, the problems of interruption are less relevant in these situations and the participants might therefore express their ideas and comments as they occur.

With regard to identification, there are various types and levels of this affordance, depending on the factors that lead group members to feel more or less identified when expressing their contributions. In this respect, Valacich, Jessup, Dennis, and Nunamaker (1992) describe two types of anonymity. First, content anonymity is defined as "the extent to which group members can identify the source of a particular contribution to the group" (p. 224), and this is achieved when embedded identifiers (which identify the source of a contribution) are absent. The second type is process anonymity, referring to "the extent to which group members can determine whether or not another group member is participating" (p. 223). In this study, we define identification as "the extent to which contributions (ideas and comments) of the participants in group work are linked to the identities of the contributors". The term "linked" in the definition is not to be understood in a solely technological sense, but may also represent a cognitive linkage made by the group members regarding the relationship between contributors and contributions. A lack of process anonymity may therefore result in interaction characterized by high identification even though the communication medium provides full content anonymity.

The distinction between process and content anonymity above underlines the importance of considering the participant's perception of media features when investigating their effects on group work (Lowry, Romano, Jenkins, \& Guthrie, 2009). With regard to identification, this implies that it is the feeling of being identified that influences one's decision on whether or not to post comments (or which words to use). Therefore, members of groups communicating on an anonymous basis can still be inhibited by group dynamics if they perceive that they are identified. Likewise, participants who can be identified (i.e., lack of content anonymity) will not necessarily be inhibited by social presence effects if they perceive that they can make contributions anonymously.

Similar social effects are relevant for both synchronicity and parallelism. Regarding the former affordance, Dennis and Valacich (1999) argue that media which enable rapid feedback create expectations of rapid feedback. These expectations will influence communication decisions, and it is thus not the media capability per se that is relevant, but rather the social mechanisms provoked. Perceptions of the degree of synchronicity of interaction are therefore essential. As regards parallelism, social rules associated with face-to-face (F2F) dialogues can be used as an example of the relevance of perceptions. In these situations, speaking while another person is speaking is possible but is not seen as good etiquette. Thus, the feeling that group members may (not) interrupt others will have consequences for their decision on whether or not to express ideas and comments as they occur. On this basis, the perceptions of media affordances are emphasized in this study.

\section{Innovative Thinking}

Innovation work in organizations is typically assumed to encompass several phases, and the process generally starts with idea generation (Blazevic \& Lievens, 2004). That is, in a problemsolving situation, the first step is to search for alternatives. Problem-solvers have to collect information that is relevant to the problem at hand and may contribute to successful change. After the search for alternatives, the problem-solvers need to select the most appropriate solution for the task. Successful completion of the idea generation phase thus entails a combination of divergent and convergent thinking (Cropley, 2006). Exercising divergent thinking involves starting with a specific problem and generating various options and (loosely associated) ideas and perspectives on the problem. It further entails shifts between mental categories and perspectives and being able to "think outside the box" (Ashton-James \& Chartrand, 2009). Divergence typically occurs in a spontaneous, free-flowing manner, such that ideas are generated in a random, unorganized order. Convergent thinking follows the divergent process and acts to narrow down the options available 
to obtain a number of "satisfying" solutions to the problem. This process implies seeing similarities and finding patterns between diverse pieces of information (Ashton-James \& Chartrand, 2009). Convergence is thus an integrating and narrowing process, and the objective is to find an appropriate or "correct" solution to a problem.

In the light of the discussion above, idea generation can be understood as a process that consists of both divergent and convergent thinking with the objective of creating the best possible idea or solution to a problem. According to Basadur, Graen, and Green (1982), it may be necessary consciously to separate divergent thinking from convergent thinking in order to prevent people from holding back ideas they think are stupid (which implies that they exercise divergent and convergent thinking interchangeably). The reason for this is that creation of significant improvements or entirely new products requires ideas that seem preposterous and unachievable at first. These researchers therefore developed a sequenced two-step thinking process called "ideation-evaluation" (i.e., production of ideas without evaluation and thereafter application of judgment to the ideas produced). Research has supported both the general separation of idea production from the evaluative processes (e.g., Cropley, 2006; Wolf \& Mieg, 2010) and the more specific ideationevaluation process (e.g., Basadur \& Finkbeiner, 1985).

Further, idea generation is both a cognitive and social process as people often work with others as part of a formal or informal group to generate ideas (Dennis, Aronson, Heninger, \& Walker Ii, 1999; Nagasundaram \& Dennis, 1993). Under these conditions, individuals first conceptualize an idea (cognitive process) and then choose whether or not to contribute it (social process) (Garfield, Taylor, Dennis, \& Satzinger, 2001). When ideas and comments are put forth, the formulations of these contributions are important for the outcome of group work. That is, the words and sentences that are used in group-based problem-solving are often critical in determining whether the problem-solvers are able to improve the situation and arrive at the best solutions. Referring to the impacts of "wrong" wordings in problem-solving, Clark (2010) and Basadur (1995b) speak of "killer phrases" in brainstorming sessions. These are expressions like "we already tried that", "it would cost too much", "all right in theory", and "yes, but...", and help to narrow down the available options. Sentences of this character are thus about convergence, meaning that they should only be used during the evaluative part of the idea generation process. The counterparts of these expressions are sentences like "how might we...", "in what kind of ways...", and "what is our real problem...", and are more challenge-oriented. This means that problems are framed in a positive manner and refer to challenges rather than unwanted difficulties that have to be overcome. Referring to this distinction, the concepts of divergent focus and convergent focus will be used as dependent variables in this study.

\section{Attitudes and Cognitive Style}

According to Basadur and Finkbeiner (1985), ideation and evaluation involve both cognitive and attitudinal elements. For example, they state that "effective ideation may require specific attitudes favoring this kind of thinking, perhaps to help participants truly 'let loose' and use more fully their unencumbered imaginations" (p. 38). Attitudes can thus be seen as antecedents of cognitive processes. Basadur et al. (1982) and Basadur and Finkbeiner (1985) therefore suggest that differences in ideation performance can be explained by differences in attitudes toward ideation. These authors identify several attitudinal constructs related to ideation, two of which are "preference for ideation" and "tendency to [not] make premature critical evaluation of ideas". Originally, the focus of the latter construct was on premature convergence. The mind-sets associated with the construct are more or less the opposite of "preference for ideation", however, and we therefore use the term "preference for evaluation" for this particular attitude.

In relation to these attitudinal factors, the concept of cognitive style is also relevant in a problemsolving context. According to Guilford (1967), people differ in their abilities to think divergently 
and convergently, and Brophy (1998) further points out that different cognitive and personality traits may accompany divergent and convergent thinking. In this respect, the AssimilatorExplorer (A-E) theory of cognitive styles (Kaufmann, 1995) describes individual differences in preferences for problem-solving strategies and distinguishes between assimilators and explorers as extreme points on a continuum. The problem-solving behavior subsumed under assimilator preference is guided by a "rule-following/rational strategy," implying that individuals with this preference will tend to follow established rules or schemes when solving problems. In contrast, the extreme explorer preference entails constantly seeking novel solution alternatives. As both cognitive styles and attitudes toward idea generation may affect divergent and convergent thinking in group-based problem-solving, the variables are included as moderators (Baron \& Kenny, 1986) in this study.

\section{Hypotheses Development}

\section{Main Effects of Communication Affordances on Innovative Thinking Processes}

Synchronicity refers to whether interaction is same-time or not and determines the extent to which participants can give immediate feedback to the messages they receive (Burgoon et al., 1999). The highest level of perceived synchronicity is thus most likely to occur when interaction takes place in real time, and accordingly the level will decrease with increasing time-lags between messages from one participant and responses to these messages from other participants. The level of synchronicity is, in other words, reversely proportional to the time that elapses before feedback can be provided. In an idea-generating context, synchronicity may be important because it influences the participants' opportunities to rehearse and reprocess messages.

Rehearsability refers to the extent to which the media enable the sender to carefully formulate a message before it is sent, which ensures that the intended meaning is expressed accurately. Rehearsing messages before sending may therefore reduce the perceived risk of receiving negative comments (which may inhibit people from promoting solutions). Low synchronous interaction enables rehearsability and tends to be less disruptive to group members (Kock, 1997), implying that it will increase the time and amount of evaluation the participants can apply to their ideas. It can also enable reprocessability, referring to the extent to which messages received from other group members can be re-examined. This may affect information processing by allowing individuals to revisit messages for further consideration and, thus, facilitates convergent thinking processes.

Whereas low synchronicity enables both rehearsability and reprocessability, high synchronicity to a lesser extent facilitates critical examination of ideas that are to be put forth (rehearsability) and evaluation of contributions from other group members (reprocessability) (DeLuca \& Valacich, 2006). The absence of these evaluative processes implies that participants do not exert judgment during idea generation, which is highlighted as a critical rule for successful ideation (Parnes \& Harding, 1992). Further, as highly synchronous interaction implies expectations of immediate feedback, the participants are likely to have a shared cognitive focus (i.e., working on the same ideas) (Ballard \& Seibold, 2004). Hitchhiking on the ideas of others is therefore likely to occur to a greater extent in high synchronous interaction, which is considered to be another important aspect of successful ideation (Parnes \& Harding, 1992). Interaction with high synchronicity may therefore have positive impacts on divergence. This leads to the following hypotheses:

Hla: Participants involved in interaction with high synchronicity have a higher "divergent focus" than participants involved in interaction with low synchronicity; and 
H1b: Participants involved in interaction with low synchronicity have a higher "convergent focus" than participants involved in interaction with high synchronicity.

Parallelism refers to the extent to which the participants in group-based problem-solving can make contributions at any time without interrupting each other. Low parallelism means that it may be problematic for the group members to communicate their ideas simultaneously (as in the situation of F2F interaction) and may, thus, lead to production blocking (occurring when verbalization of ideas as they occur is prevented). In these situations, a participant may forget an idea while waiting for a turn to speak or may devote attention to remembering an idea and, thus, become too distracted to generate new ideas (Diehl \& Stroebe, 1987; Nunamaker, Dennis, Valacich, \& Vogel, 1991; Nunamaker, Dennis, Valacich, Vogel, \& George, 1991). Participants involved in interaction with low parallelism may also be more self-critical as they attract the other group members' full attention when contributing their ideas. High parallelism, on the other hand, means that the participants do not have to take turns in utterance of contributions. This reduces conflict for the communication channel and thereby mitigates production blocking (Murthy \& Kerr, 2003; Shepherd, Briggs, Reinig, Yen, \& Nunamaker, 1995) and also contributes to diversity by allowing group members to multitask (DeLuca, 2008). In these situations, it can be difficult to reprocess ideas that have been put forth while at the same time being attentive to the ongoing discussions. There is therefore less room for critical evaluation of all ideas that are proposed. Further, according to Van de Ven, Polley, Garud, and Venkataraman (1999), an increase in the number of initiatives undertaken by a large number of interacting people enhances the probability of their stimulating innovation. We therefore propose that:

H2a: Participants involved in interaction with high parallelism have a higher "divergent focus" than participants involved in interaction with low parallelism; and

H2b: Participants involved in interaction with low parallelism have a higher "convergent focus" than participants involved in interaction with high parallelism.

Individuals are generally concerned about how others perceive and think of them and can, therefore, be reluctant to express unorthodox thoughts (Collaros \& Anderson, 1969; DeSanctis \& Gallupe, 1987). Anonymity can influence the perceptions and social interactions of individual group members (Pinsonneault \& Heppel, 1997) and, thereby, also the decisions of whether or not to contribute and express ideas (Connolly, Jessup, \& Valacich, 1990; Diehl \& Stroebe, 1987; Nunamaker, Dennis, Valacich, \& Vogel, 1991). Several researchers have found that anonymity encourages full participation of group members who otherwise would have been socially inhibited from expressing unpopular, novel or heretical opinions (Kraemer \& King, 1988; Nunamaker, Applegate, \& Konsynski, 1988). Groups using anonymous electronic meeting systems have also been found to generate more critical comments than groups using systems where the author of each comment was identified (Connolly et al., 1990; Jessup, Connolly, \& Galegher, 1990; Valacich, Dennis, \& Numamaker, 1992). Working in a group where the identities of the participants are known might therefore inhibit a contributor who anticipates embarrassment, hostile evaluation, or conformity pressures to propose unusual ideas. In contrast, anonymity may lead to a reduction of these mechanisms. That is, it is reasonable to believe that the fear of negative comments will be lower if the interacting parties do not know the identity of each other, even though the degree/strength of the critical comments may be greater in anonymous environments than in identified environments. The barriers related to idea expression that group members experience will thus be lower if the contributions can be made anonymously. This may be particularly important considering that the most preposterous ("out of the box") ideas are needed to create significant improvements or entirely new products (Basadur et al., 1982). In this sense, anonymity may facilitate high-quality ideative thinking and behavior. In contrast, the social mechanisms (e.g., fear of criticism) that come into play in identified environments may result in more self-critical thinking and behavior, and the contributions may therefore be more evaluative in character. Thus: 
H3a: Participants involved in interaction with low identification have a higher "divergent focus" than participants involved in interaction with high identification; and

H3b: Participants involved in interaction with high identification have a higher "convergent focus" than participants involved in interaction with low identification.

\section{Moderating Effects of Attitudes and Cognitive Style}

As discussed earlier, the degree of synchronicity is important for the possibilities for rehearsal of ideas before they are contributed. As people located on the explorative side of the assimilationexploration continuum seek novel solutions and variation (Kaufmann, 1995) and are less concerned with accuracy, rehearsability, and reprocessability, explorative people may be more comfortable with a communication process characterized by immediate feedback. Their preferences for non-critical idea-generation are, in other words, in accordance with high synchronous interaction. Likewise, high synchronous interaction also tallies with high preferences for ideation (free flow of ideas without making judgments and evaluations during idea generation), and manifestations of divergent thinking may, for this reason, become more distinct as the individuals' preferences for ideation increase. Thus:

H4a: The effects of synchronicity on "divergent focus" will increase with

(a) increasing explorative cognitive styles

(b) increasing preferences for ideation.

As assimilators prefer to follow established rules or schemes, and explorers have a strong need for novelty and stimulus variability (Kaufmann \& Martinsen, 1993), the opportunity to rehearse and critically evaluate a message before sending it to others is likely to be more important to people on the "assimilative side" of the assimilation-exploration continuum than it is for explorative individuals. Assimilators may for this reason, to a greater extent than explorers, appreciate the opportunities for rehearsing and reprocessing ideas and comments that are present in low synchronous interaction. Consequently, we may find that the wordings of contributions from assimilators are more evaluative in character. Further, as low synchronicity renders possible evaluative thinking (reprocessing and rehearsing), low synchronous interaction may be more suitable for individuals with a high preference for evaluation than for people with a low preference for evaluation. Thus:

H4b: The effects of synchronicity on "convergent focus" will increase with

(a) increasing assimilative cognitive styles

(b) increasing preferences for evaluation.

High parallelism is associated with free flow of ideas and thus also a greater amount of information that can be simultaneously distributed to many participants. We may therefore argue that individuals comfortable in situations where neither the information flow nor the information "content" follows predefined structures will be more comfortable with highly parallel interaction than people who prefer structured interaction. Moreover, this increase in information flow and interaction opportunities also facilitates hitchhiking on other participants' ideas and reduces evaluation apprehension, concentration blocking, and air-time fragmentation. As these elements are positive for the ideative part of idea generation, the influence of a high degree of parallelism on all of these group dynamics may be more valued by explorers and individuals with high preferences for ideation. Consequently, the contributions in high parallel interaction will be more divergent for highly explorative and "ideative" individuals. Therefore:

H5a: The effects of parallelism on "divergent focus" will increase with

(a) increasing explorative cognitive styles

(b) increasing preferences for ideation. 
Because of turn-taking (interruption) issues, evaluative activities like rehearsability and reprocessability may be more salient in situations with low parallelism than in situations with high parallelism. Following the arguments above, both assimilative cognitive styles and high preferences for evaluation are more in accordance with such an interaction environment. That is, manifestations of preferences for evaluative thinking are likely to be more apparent in low parallel interaction. Therefore:

H5b: The effects of parallelism on "convergent focus" will increase with

(a) increasing assimilative cognitive styles

(b) increasing preferences for evaluation.

Also, with regard to identification, it is likely that individuals' cognitive styles and attitudes toward idea generation will strengthen the main effects proposed in hypotheses $3 \mathrm{a}$ and $3 \mathrm{~b}$. This means that an interaction environment with a low degree of identification is more suitable for explorers and individuals with high preferences for ideation. That is, low identification of participants in group-based problem-solving can result in situations where explorers and highly ideative people can more freely "live out" their preferences for going off in new directions, decreasing the inhibition explorers and ideative individuals may experience in situations with high identification. Therefore:

H6a: The effects of identification on "divergent focus" will increase with

(a) increasing explorative cognitive styles

(b) increasing preferences for ideation.

In a situation with high identification, individuals may become more self-aware and experience more conformance pressure and evaluation apprehension than in a situation with low identification. As stated in $\mathrm{H} 3 \mathrm{~b}$, this may increase the evaluative and convergent activities of problemsolving. Further, as the Assimilator-Explorer Theory posits that assimilators are more conformist and rule-bound than explorers (Martinsen, 1995), individuals with the former cognitive style would probably be more comfortable with the effects of high identification than individuals located on the explorative side of the cognitive style continuum. This will probably also be the case for individuals with high preferences for evaluation. Therefore:

H6b: The effects of identification on "convergent focus" will increase with

(a) increasing assimilative cognitive styles

(b) increasing preferences for evaluation.

Figure 1 provides an overview of the proposed hypotheses. 


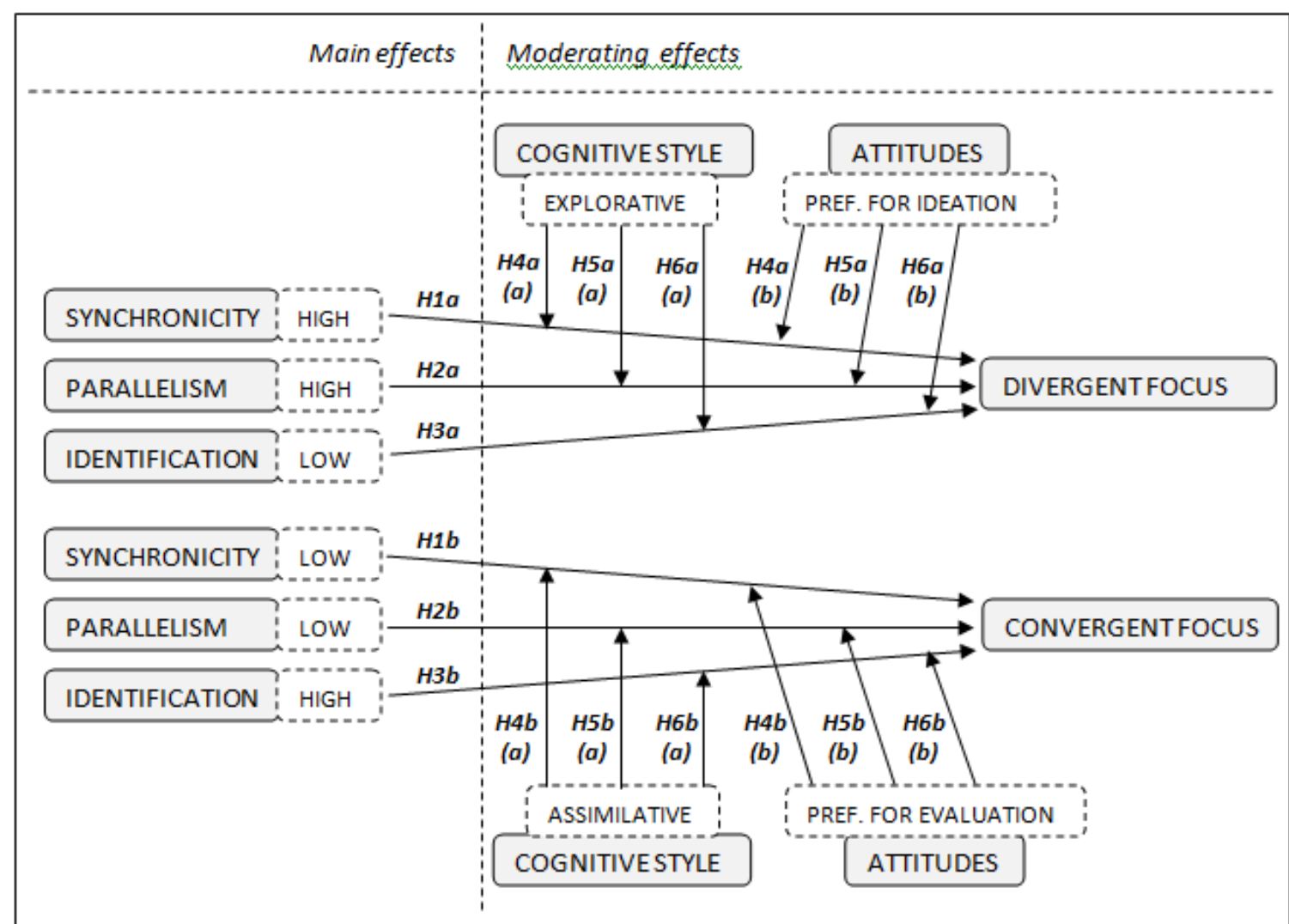

Figure 1. Overview of hypotheses.

\section{Method}

\section{Research Design and Participants}

In order to test the hypotheses, the design of the study had to ensure that the variation in media affordances (high and low) were sufficient for hypothesis testing. That means that the research design had to involve computer-mediated collaborative group work where the communication media (technological configurations) ensured sufficient variance of the participants' perceptions of synchronicity, parallelism, and identification. Further, adequate measurement of all variables in the study (illustrated in Figure 1) was also a fundamental requirement.

On the basis of these requirements, an experiment involving computer-mediated group work was designed. A total of 95 graduate and undergraduate students (56\% male and $44 \%$ female) were involved in the experiment, and the participants were recruited from various courses within the field of strategy and management at a business school. The assignment of individuals to experimental groups was accomplished in two steps.

First, the participants were randomly distributed into problem-solving groups with three to five participants. There were a total of 27 problem-solving groups in the experiment. Second, each of these groups was assigned to one of the three experimental conditions (Figure 2). That is, one experimental condition consisted of several (eight to ten) problem-solving groups. Within the experimental conditions, the communication affordances were manipulated in the same manner for all problem-solving groups. As illustrated in Figure 2, experimental condition 1 consisted of eight 
groups ( 32 participants in total), condition 2 consisted of 10 groups ( 32 participants in total), and condition 3 consisted of nine groups (31 participants in total).

\begin{tabular}{|c|c|c|c|}
\hline & Condition 1 & Condition 2 & Condition 3 \\
\hline Synchronicity & Low & High & High \\
\hline Parallelism & High & Low & High \\
\hline Identification & High & Low & Low \\
\hline & $\sqrt{1}$ & $\sqrt{l}$ & $\Omega$ \\
\hline Number of problem-solving groups & 8 & 10 & 9 \\
\hline Number of participants & 32 & 32 & 31 \\
\hline
\end{tabular}

Figure 2: Experimental design

\section{Procedure and Task}

The problem-solving sessions were carried out by use of discussion forums and electronic notepads as collaborative tools in Groove (Internet-based group collaboration software). The configuration of the software was carried out prior to the sessions. This included both the specific setup of collaborative tools (discussion forums and notepads) and also the link between computers pertaining to the specific problem-solving groups. As the participants were told which computer to use as they entered the room, they were randomly assigned to the problem-solving groups.

With regard to training and instructions, a general introduction to the software was given to the participants in plenum. In addition, a letter explaining the specific use of the software and the task to be solved was handed out.

The group task was to discuss and propose potential solutions to the problem of private (noncommercial) Internet-based sharing of music files. More specifically, the groups had to come up with suggestions for products and services that were advantageous for both the industry (i.e., musicians and companies) and users of file-sharing services. Accordingly, there was neither a single "correct" solution to the problem nor an expectation that the group members would agree on a feasible solution within the timeframe of the experiment as this would have "encouraged" convergent thinking.

The groups were given 30 minutes to discuss the problem. After finishing group discussions, they were asked to complete questionnaires measuring perception of affordances, cognitive style, and attitudes toward idea generation. The questionnaire data and the transcripts from the group discussions constituted primary data for the research.

The total experimental sessions (including instructions and completion of questionnaires) were completed in 45 to 50 minutes. After the sessions, the students were given a small reward for their participation.

\section{Operationalization and Manipulation of Affordances}

The various components of the software allowed for different configurations to be used in order to create adequate variation in the communication affordances. The groups in conditions 1 and 3 communicated by use of discussion forums, whereas groups in condition 2 communicated by use of shared notepads. Text-based communication was chosen because of the need to create variance in synchronicity, parallelism, and identification while holding the levels of other communication affordances constant across conditions. For example, a comparison between diverse media like 
F2F and text-based chat communication would imply significant differences in the levels of media and information richness (Münzer \& Borg, 2008; Münzer \& Holmer, 2009) (an affordance that Burgoon et al. (1999) define as "whether the format utilizes one or more modalities such as text, audio, visual, or touch, and the extent to which it supports symbol variety to present 'rich' or 'poor' social information" (p. 36))

Based on the conceptual definition of synchronicity, the concept is operationalized as "the time delay between writing of a message by one participant to the reading of the message by another participant." Different levels of synchronicity were ensured by manipulating the time that elapsed between the sending of a message from one participant and the receipt by another participant. More specifically, problem-solving groups in conditions 2 and 3 were working online, and a low time delay between production and reception of messages was thus achieved. In contrast, groups in condition 1 were working offline, except for brief online periods every three minutes when the contributions (ideas, comments, etc.) were transmitted. For these groups, the time delays between message production and message reception were therefore higher than for problem-solving groups in conditions 1 and 2.

Parallelism refers to the participants' opportunities to be engaged in simultaneous dialogues in a group-based problem-solving situation and is operationalized as "the degree to which it is possible for the participants to post their ideas and comments at the same time without interrupting others." For groups in conditions 1 and 3, high parallelism was implemented as discussion forums that allowed for simultaneous postings, whereas problem-solving groups in condition 2 (low parallelism) communicated by typing messages in a shared text editor. The use of this communication tool meant that the contributions were displayed to the whole group as they were typed. Thus, two or more participants typing at the same time would be similar to simultaneous speaking in F2F interaction and could thus be regarded as "mutual" interruption. Simultaneous typing also caused the texts to be juxtaposed over each other, thus making them difficult or impossible to read.

Identification is defined as the extent to which contributions (ideas and comments) of the participants in group work are linked to the identities of the contributors. Based on this definition, the affordance is operationalized as "whether or not the identities of the participants in a group-based problem solving situation are displayed along with (and thus linked to) the contributions of the participants". In order to ensure high perceived identification (groups in condition 1), the names of the contributors were displayed together with their postings. This was not the case for the problem-solving groups in the other conditions, thus ensuring low identification.

\section{Measurement}

The experimental setup, including configuration of collaborative tools and work process instructions, was designed to create variance in perceptions of synchronicity, parallelism, and identification.

As discussed earlier, perceptions of media affordances are central to the investigation of effects of communication characteristics on participants' formulations of contributions (divergent and convergent focus). On this basis, a scale for measuring perception of affordances was developed, and Table 1 provides an overview of the indicators that pertain to the three affordances. 
Table 1: Measures of communication affordances

\section{INDICATORS}

The other participants in the group knew which contributions were mine

It was easy to know who had presented an idea/comment

It was easy to relate a specific contribution to the person who proposed it

The contributors were generally unknown [reverse/negative indicator]

The collaborative tool made it possible for me to present my contributions without the other participants knowing that they were mine $[r e-$ verse/negative indicator]

I could provide immediate feedback on other group members' contributions.

I could get immediate feedback on my contributions.

My response time to contributions from other participants could be very low [reverse/negative indicator]

The response time of the other group participants to my contributions could be very low [reverse/negative indicator]

Thoughts and ideas that popped up could be presented without interrupting other group participants

Ideas and thoughts that popped up could be framed immediately without risking everyone speaking at once

It happened that I delayed proposing thoughts and ideas that popped up because I didn't want to interrupt other group participants [reverse/negative indicator]

$\%$ of variance extracted

\section{FACTORS}

\section{2}

$h^{2} \quad$ Identification Synchronicity Parallelism

.67

.81

.08

.07

.75

.81

.19

.13

.70

.83

.04

.72

.82

$-.04$

$-.21$

.71

.82

$-.14$

$-.08$

.78

.01

.88

.06

.82

$-.07$

.90

.03

.66

.14

.79

.13

.68

.75

.71

.01

.07

.69

.04

$-.06$

71.6

28.9
.83

.84

.83

.05

16.2

As shown in Table 1, factor analysis of the indicators extracted three factors with eigenvalues equal to or above one (3.47, 3.18 and 1.94$)$, accounting for approximately $72 \%$ of the variance. Satisfactory communalities $\left(\mathrm{h}^{2}\right)$ for all indicators were obtained. Further, a satisfactory discriminant and convergent validity of the indicators was obtained, and index variables of the items pertaining to synchronicity, parallelism, and identification were created. Cronbach's alphas of the indicators were 0.87 (synchronicity), 0.77 (parallelism), and 0.88 (identification). 
The differences in perceptions of the independent variables caused by the manipulations were applied to create dichotomous variables of synchronicity, parallelism, and identification. Each respondent in this way characterized the levels of the independent variables as low or high, which again were applied in the tests of hypotheses. T-tests to investigate the differences in perceived values of the independent variables between groups used in the hypothesis testing showed that the differences in scores of the focused independent variables were significant, whereas the differences in scores of the unfocused variables were not significant (Table 2). The independent variables were thus suitable for testing the hypotheses.

Table 2: Test of differences in perceptions of media affordances

\begin{tabular}{cccccc}
\multirow{2}{*}{ GROUP } & VARIABLE & GROUP MEANS & \multirow{t}{*}{} & $\boldsymbol{p}$ \\
& & HIGH & LOW & & \\
\multirow{3}{*}{ Synchronicity } & Synchronicity & 4.43 & 2.80 & -12.94 & 0.00 \\
& Parallelism & 3.81 & 3.65 & -0.72 & 0.48 \\
& Identification & 3.12 & 2.98 & -0.60 & 0.57 \\
& Synchronicity & 3.76 & 3.60 & -0.82 & 0.41 \\
Parallelism & Parallelism & 4.49 & 2.82 & -12.18 & 0.00 \\
& Identification & 3.10 & 3.00 & 0.43 & 0.66 \\
& Synchronicity & 3.62 & 3.77 & 0.71 & 0.48 \\
Identification & Parallelism & 3.73 & 3.74 & 0.01 & 0.99 \\
& Identification & 4.09 & 2.09 & -18.15 & 0.00
\end{tabular}

The dependent variables (divergent focus and convergent focus) refer to the nature of the participants' thinking processes during idea generation. In a group-based problem-solving context, the selections of words and sentences can be perceived as manifestations of the contributors' thinking processes. Words and sentences that reflect divergent thinking generate variability. These formulations are not about judgments and criticism, but rather encourage exploration of numerous ideas. In this study, individuals whose wordings are of this character are perceived to have a divergent focus on the idea generation process. These words and sentences are free of judgment and evaluation, but rather seek to explore fuzzy situations, facts, statements, and ideas. On the other hand, convergent focus involves use of formulations that generate orthodoxy. These are words and phrases that act to narrow down the available solutions to a problem, and use of such wordings will be regarded as a result of a convergent focus.

In order to capture the participants' divergent and convergent focus, it was necessary to investigate their contributions to the group work. Content analysis of the transcripts from the group work was therefore undertaken. All transcripts were analyzed and coded by three people independently. Prior to the content analysis, the coders were given an introduction to the underlying theoretical basis of the dependent variables, including the distinction between divergence and convergence in general, and use of wordings that indicated divergent focus and convergent focus in particular. In this respect, words and sentences representing the two distinct thinking processes were appraised and discussed by the coders prior to the coding process in order to create a mutual understanding of the concepts (a list of language manifestations of convergent focus ("killer phrases") is given in the Appendix).

The coders were, in the first instance, instructed to read the transcripts and mark the phrases and words that indicated divergent focus and convergent focus. Afterwards, they were instructed to go 
through their markings and assess the highlighted sentences/words on a five-point scale ranging from high to low degrees of divergence/convergence.

The dependent variables were thereafter calculated from the assessments of the coders. The arithmetical means of the divergent and convergent gradings for all three coders were weighted according to the number of divergent and convergent utterances (i.e., a word, sentence, or a phrase assessed as either divergent or convergent by a coder) relative to the total number of contributions. The dependent variables computed were thus based on a combination of the degree of divergent/convergent focus (the strength of the utterances) and the frequency of divergent/convergent utterances in the group work.

As regards the moderating variables, measures validated in previous research were applied. In order to measure the participants' cognitive styles, the instrument of the Assimilator-Explorer theory (Kaufmann \& Martinsen, 1993) was applied. The total inventory consists of 34 questions to be judged for appropriateness on a five-point Likert-scale from "very poor description" to "very good description." Attitudes toward idea generation were measured with the Basadur 14 Item Ideation-Evaluation Preference Scale (Basadur, Taggar, \& Pringle, 1999).

In sum, dichotomous variables of communication media affordances and continuous variables of divergent/convergent focus, cognitive styles, and attitudes toward idea generation were constructed. The measures were adequate for investigations of the hypothesized relationships depicted in Figure 1. Multivariate analysis of variance (MANOVA) by use of SPSS was conducted in order to test whether there were significant differences in divergent/convergent focus between high and low levels of synchronicity, parallelism, and identification (H1 to H3). In testing the moderating hypotheses (H4 to H6), analysis of covariance (ANCOVA) was applied in order to test whether the effects of media affordances on divergent/convergent focus were significantly different depending on the participants' cognitive styles and attitudes toward idea generation.

\section{Results}

First, the main hypotheses (H1 to H3) were tested by MANOVA. The results from the betweensubjects tests of the main hypotheses are presented in Table 3. With regard to synchronicity and identification, none of the relationships are significant, and the results therefore lend no support to hypotheses H1a, H1b, H3a, and H3b. For parallelism, the results show that individuals involved in interaction with high parallelism have a significantly higher divergent focus than individuals involved in interaction with low parallelism. This lends support to $\mathrm{H} 2 \mathrm{a}(\mathrm{p}=0.05)$. The results also show, however, that individuals involved in interaction with high parallelism have a significantly higher convergent focus than individuals involved in interaction with low parallelism $(p=0.01)$, which is opposite to the hypothesized relationship. $\mathrm{H} 2 \mathrm{~b}$ should therefore also be rejected.

Table 3: Main effects of independent variables - between subjects

\begin{tabular}{ccccccc}
$\begin{array}{c}\text { DEPENDENT } \\
\text { VARIABLE }\end{array}$ & \multicolumn{2}{l}{ INDEPENDENT VARIABLE } & F-VALUE & $\boldsymbol{p}$ & \multicolumn{3}{c}{ GROUP MEANS } \\
& & & & & HIGH & LOW \\
Synchronicity & $\mathrm{H} 1 \mathrm{a}$ & Divergent focus & 0.15 & 0.70 & $1.48(\mathrm{n}=50)$ & $1.42(\mathrm{n}=41)$ \\
& $\mathrm{H} 1 \mathrm{~b}$ & Convergent focus & 0.92 & 0.34 & $3.37(\mathrm{n}=50)$ & $3.68(\mathrm{n}=41)$ \\
\multirow{3}{*}{ Parallelism } & $\mathrm{H} 2 \mathrm{a}$ & Divergent focus & 4.06 & 0.05 & $1.61(\mathrm{n}=50)$ & $1.27(\mathrm{n}=41)$ \\
& $\mathrm{H} 2 \mathrm{~b}$ & Convergent focus & 11.13 & 0.01 & $3.96(\mathrm{n}=50)$ & $2.95(\mathrm{n}=41)$ \\
\multirow{2}{*}{ Identification } & $\mathrm{H} 3 \mathrm{a}$ & Divergent focus & 0.20 & 0.66 & $1.49(\mathrm{n}=44)$ & $1.42(\mathrm{n}=47)$ \\
& $\mathrm{H} 3 \mathrm{~b}$ & Convergent focus & 1.99 & 0.16 & $3.74(\mathrm{n}=44)$ & $3.29(\mathrm{n}=47)$
\end{tabular}


Analysis of covariance (ANCOVA) was thereafter conducted in order to test the moderating hypotheses (univariate analyses of covariance were applied in order to include only the relevant covariates in the tests).

Table 4 shows the results of analyses of covariance with divergent focus as dependent variable.

Table 4: Effects of media affordances and covariates on divergent focus

\section{DEPENDENT \\ VARIABLE}

$\begin{array}{ccccc} & & \text { Synchronicity } & 0.96 & 0.33 \\ & \text { H4a-a } & \text { Synchronicity * Assimilators/explorers } & 2.30 & 0.13 \\ \text { H4a-b } & \text { Synchronicity * Ideation } & 0.05 & 0.83 \\ & & \text { Parallelism } & 0.01 & 0.95 \\ \text { Divergent focus } & \text { H5a-a } & \text { Parallelism * Assimilators/explorers } & 0.06 & 0.81 \\ & \text { H5a-b } & \text { Parallelism * Ideation } & 0.58 & 0.45 \\ & & \text { Identification } & 1.31 & 0.26 \\ & \text { H6a-a } & \text { Identification * Assimilators/explorers } & 3.00 & 0.09 \\ \text { H6a-b } & \text { Identification * Ideation } & 0.00 & 0.97\end{array}$

The first three rows in Table 4 show the test results of moderating effects (cognitive style and preference for ideation) on the relationship between synchronicity and divergent focus. As can be seen, none of the effects turned out to be significant (H4a-a: $p=0.13$ and H4a-b: $p=0.83$ ) and hypothesis $\mathrm{H} 4 \mathrm{a}$ is thus not supported. Likewise, as can be seen in rows 4 to 6 , the results show that there is no significant moderating effect on the relationship between parallelism and divergent focus (H5a-a: $p=0.81$ and H5a-b: $p=0.45)$. H5a should therefore also be rejected. It should further be noted that the main effect of parallelism on divergent focus reported earlier also turned out to be insignificant when the covariates were included in the model $(\mathrm{p}=0.95)$.

Finally, the last three rows in Table 4 show that H6a should be rejected as there are no significant moderating effects on the relationship between identification and divergent focus (H6a-a: $p=0.09$ and H6a-b: $\mathrm{p}=0.97)$. Although insignificant, the interaction term between identification and cognitive style $(p=0.09)$ might be interpreted as an indication of a relationship and should be noted. Analyses of simple effects show that the level of divergent focus in situations with high identification decreases with increasing explorative styles. In situations with low identification, the level of divergent focus increases with increasing explorative cognitive styles. The opposite relationships are found for assimilators. Thus, potential positive effects of low identification on divergent focus could increase with increasing explorative cognitive styles, which is in accordance with the hypothesized relationship (H6a-a).

Table 5 shows the results of analyses of covariance with convergent focus as dependent variable. 
Table 5: Effects of media affordances and covariates on convergent focus

\section{DEPENDENT VARIABLE}

$\begin{array}{lcccc}\begin{array}{l}\text { DEPENDENT } \\ \text { VARIABLE }\end{array} & & \text { INDEPENDENT VARIABLES } & \text { F- } & p \\ & & \text { AND MODERATORS } & \text { VALUE } & \\ & & \text { Synchronicity } & 3.68 & 0.06 \\ & \text { H4b-a } & \text { Synchronicity * Assimilators/explorers } & 0.23 & 0.63 \\ & \text { H4b-b } & \text { Synchronicity * Evaluation } & 3.95 & 0.05 \\ & & \text { Parallelism } & 0.49 & 0.49 \\ \text { Convergent focus } & \text { H5b-a } & \text { Parallelism * Assimilators/explorers } & 0.42 & 0.52 \\ & \text { H5b-b } & \text { Parallelism * Evaluation } & 1.20 & 0.28 \\ & & \text { Identification } & 0.37 & 0.55 \\ & \text { H6b-a } & \text { Identification * Assimilators/explorers } & 1.85 & 0.18 \\ & \text { H6b-b } & \text { Identification * Evaluation } & 1.74 & 0.19\end{array}$

\section{INDEPENDENT VARIABLES} AND MODERATORS

Synchronicity

Rows 1 to 3 in Table 5 show the results of the tests of moderating effects of cognitive style and preference for evaluation on the relationship between synchronicity and convergent focus. The results show that the hypothesized moderating effect of cognitive style is not supported (H4b-a: $\mathrm{p}=0.63$ ). As seen in row 3 , however, there is a significant interaction term between synchronicity and preference for evaluation $(\mathrm{p}=0.05)$. Analyses of simple effects show that low synchronicity results in higher convergent focus for individuals with low preferences for evaluation, and that the level of convergent focus decreases with increasing preferences for evaluation. The opposite is found for individuals involved in high synchronous interaction (an increase in preference for evaluation is accompanied with an increase in convergent focus). The effects of synchronicity on convergent focus thus seem to increase with decreasing preferences for evaluation, and this is opposite to the hypothesized effect of this covariate. H4b-b should therefore also be rejected. It should further be noticed that the main effect of synchronicity strengthens (but remains insignificant, $\mathrm{p}=0.06$ ) when cognitive style and preference for evaluation are controlled for (estimated marginal means are 3.34 and 3.67 for high and low synchronicity respectively).

Rows 4 to 6 in Table 5 show that neither cognitive style nor preference for evaluation has significant moderating effects on the relationship between parallelism and convergent focus. H5b is therefore not supported. The results further show that the main effect of parallelism on convergent focus reported earlier also turns out to be insignificant $(p=0.49)$ when the covariates are included in the model. With regard to identification, rows 7 to 9 show that none of the effects turned out to be significant (H6b-a: $p=0.18$ and H6b-b: $p=0.19$ ) and H6b is thus not supported.

Table 6 provides a summary of the results of hypothesis testing. As can be seen, none of the hypotheses were supported. It should also be noted that one significant effect opposite to the expected direction was found. 
Table 6: Summary of tests of hypotheses

\begin{tabular}{|c|c|c|c|c|c|}
\hline \multirow[t]{4}{*}{ DEPENDENT } & INDEPENDENT & MODERATOR & HYP. & RESULT & COMMENT \\
\hline & Synchronicity & - & H1a & n.s & \\
\hline & Parallelism & - & $\mathrm{H} 2 \mathrm{a}$ & n.s & \\
\hline & Identification & - & $\mathrm{H} 3 \mathrm{a}$ & n.s & \\
\hline \multirow{6}{*}{$\begin{array}{l}\text { Divergent fo- } \\
\text { cus }\end{array}$} & \multirow{2}{*}{ Synchronicity } & Explorative & $\mathrm{H} 4 \mathrm{a}-\mathrm{a}$ & n.s & \\
\hline & & Pref. for ideation & $\mathrm{H} 4 \mathrm{a}-\mathrm{b}$ & n.s & \\
\hline & \multirow{2}{*}{ Parallelism } & Explorative & H5a-a & n.s & \\
\hline & & Pref. for ideation & H5a-b & n.s & \\
\hline & \multirow[t]{2}{*}{ Identification } & Explorative & H6a-a & n.s & $\begin{array}{l}\text { Indication of relationship } \\
(p=0.09)\end{array}$ \\
\hline & & Pref. for ideation & H6a-b & n.s & \\
\hline \multirow{9}{*}{$\begin{array}{l}\text { Convergent } \\
\text { focus }\end{array}$} & Synchronicity & - & $\mathrm{H} 1 \mathrm{~b}$ & n.s & $\begin{array}{l}\text { Indication of relationship } \\
(\mathrm{p}=0.06)\end{array}$ \\
\hline & Parallelism & - & $\mathrm{H} 2 \mathrm{~b}$ & n.s & \\
\hline & Identification & - & $\mathrm{H} 3 \mathrm{~b}$ & n.s & \\
\hline & \multirow[b]{2}{*}{ Synchronicity } & Assimilative & $\mathrm{H} 4 \mathrm{~b}-\mathrm{a}$ & n.s & \\
\hline & & $\begin{array}{l}\text { Pref. for evalua- } \\
\text { tion }\end{array}$ & $\mathrm{H} 4 \mathrm{~b}-\mathrm{b}$ & n.s & $\begin{array}{l}\text { Sig. relationship in oppo- } \\
\text { site direction }(\mathrm{p}=0.05)\end{array}$ \\
\hline & \multirow{3}{*}{ Parallelism } & Assimilative & $\mathrm{H} 5 \mathrm{~b}-\mathrm{a}$ & n.s & \\
\hline & & $\begin{array}{l}\text { Pref. for evalua- } \\
\text { tion }\end{array}$ & H5b-b & n.s & \\
\hline & & Assimilative & H6b-a & n.s & \\
\hline & Identification & $\begin{array}{l}\text { Pref. for evalua- } \\
\text { tion }\end{array}$ & H6b-b & n.s & \\
\hline
\end{tabular}

\section{Discussion}

On an overall basis, the results provided little support for the anticipated impacts of communication affordances on innovative thinking processes. The first point to address is, therefore, that the theoretical underpinnings of the hypotheses should be critically reviewed, as other factors not focused on in the study may be more influential for innovative thinking and behavior in textbased computer-mediated collaborative work. For example, several group characteristics can affect both dynamics and outcomes of group-based problem-solving, and factors like group size, proximity, composition, and cohesiveness have been shown to influence the way group members act (Nunamaker, Dennis, Valacich, \& Vogel, 1991).

Regarding group size, Lowry et al. (2009) argue that large CMC-supported groups are more susceptible to interaction process losses. Similarly, Steiner (1972) claims that an increase in group size typically results in accelerating increases in process losses, and that group size will reach a threshold beyond which productivity will decrease. Group size may therefore be significant for the effects of communication affordances on innovative thinking processes. For example, in smaller groups it may still be possible for the participants to identify the contributors even if the identities are not linked with the contributions. Larger groups would thus enhance the benefits 
and drawbacks (potential gains and process losses) of anonymous problem-solving groups. Likewise, effects of parallelism and synchronicity on divergent and convergent thinking may also depend on group size as the process losses related to these affordances may be more significant for larger groups.

Another factor that could explain the lack of significant effects is the nature of the task. As described earlier, the group task was to discuss and propose potential solutions to the problem of non-commercial Internet-based sharing of music files. This kind of task is not very representative for the tasks most often applied in research on problem-solving and creativity in groups, which are typically designed in ways that encourage highly ideative (out-of-the-box) thinking. For example, a typical task applied in creativity research is the "additional thumbs problem" (see e.g., Litchfield, 2009; Paulus \& Dzindolet, 1993), involving brainstorming about what would happen if everyone had an extra thumb on their hand. In this study, a setting that encouraged highly ideative thinking and utterance of preposterous ideas (eliciting opposing evaluative thinking) was not constructed. Thus, the scope of the idea-generation process may have been too small for the affordances to have any significant impacts on divergent and convergent thinking.

Some relationships that were revealed should be elaborated, however. First, analysis of covariance indicated that high synchronous interaction is accompanied by a low convergent focus when preference for evaluation and cognitive style are at their mean levels. The effect is not significant $(p=0.06)$ and should therefore be interpreted with caution. Without drawing any clear-cut conclusions, one can say that the relationship indicates that the level of convergent focus can be reduced by increasing the level of synchronicity in group interaction. As described in the theoretical section, one feasible explanation for this is that the abilities for reprocessability and rehearsability are reduced in this communicative setting. In other words, rapid responses to ideas and comments are expected in high synchronous interaction, which again reduce the level of convergent thinking.

Further, the analyses showed that preference for evaluation plays an important role regarding convergent focus. An increase in this attitude has different effects on convergent focus depending on the level of synchronicity of the interaction. In H4b, it was predicted that the difference between high and low synchronicity regarding convergent focus would be strengthened with increasing preferences for evaluation. The rationale underlying this hypothesis was that both low synchronicity and high preferences for evaluation support evaluative thinking processes and activities and, thus, result in higher convergent focus. The interaction effects, however, are contrary to the hypothesized relationships. This may indicate that the effect of the level of synchronicity on convergent thinking is secondary to the individuals' preferences for evaluation. That is, preferences for evaluation are more influential for evaluative thinking than the process losses resulting from synchronicity variations, as discussed in the hypothesis section. We also see, however, that the difference in convergent focus between groups with low and high synchronicity is greater for individuals with low preferences for evaluation. It therefore seems that the degree of synchronicity is more influential (for convergent focus) for individuals with low preferences for evaluation than for individuals with high preferences for evaluation. Thus, for individuals who score low on preference for evaluation, the degree of synchronicity seems to represent a factor that may influence the level of convergent focus in group discussions. For highly evaluative individuals on the other hand, the degree of synchronicity plays a minor role. Drawing on the rationale underlying the hypothesis, this indicates that communication media which do not facilitate evaluative thinking processes (e.g., reprocessability and rehearsability) may influence the convergent focus of group members low on preference for evaluation.

The results also indicated that individuals' cognitive styles are important for divergent focus, and that a movement towards the explorative end of the assimilator-explorer continuum had different effects in situations of high versus low identification. The level of divergent focus decreases with 
increasing explorative cognitive styles in situations with high identification, whereas divergent focus increases as the level of explorative cognitive style increases in situations with low identification. It should be noted that this interaction effect is not significant $(p=0.09)$ and should therefore be interpreted as an indication rather than a confirmation of a relationship between the variables. This indication is in accordance with the hypothesized relationship between these variables. Causes underlying this relationship can probably be attributed to both communication process factors and individual factors. When analyzing the nature of the highly anonymous communication environment, on the one hand, and the qualities of highly explorative cognitive styles, on the other, we find that both elements support/enhance ideative thinking and behavior. Group dynamics caused by a low degree of identification (low evaluation apprehension, low fear of receiving negative and hostile comments, low conformity pressure, etc.), increase the likelihood of achieving a high divergent focus in group interaction. These elements, again, are more appreciated by explorers as they prefer to investigate novel solutions in problem-solving. Interestingly, the opposite relationship was found in situations with high identification, indicating that the level of divergent focus is reduced as the level of explorative cognitive styles increases. This shows that the role of anonymity is particularly important for group members with explorative cognitive styles when it comes to achieving a high divergent focus.

Although few overall differences between high and low levels of synchronicity, parallelism, and identification were found, the study indicates that communication affordances may influence message construction in group work. That is, the results indicate that both synchronicity and anonymity may be influential for selection of words and sentences when composing a message and that individual characteristics are important in this respect. These affordances are thus relevant for the process of preparing information for transmission in group collaboration. Theories seeking to explain how communication media influence group dynamics and performance should therefore consider synchronicity and anonymity as relevant media variables, as well as attitudes towards idea generation and cognitive styles as important individual factors. As the content of messages in the next instance may influence the process of developing a shared understanding among group members, this further emphasizes that information construction is a central concept when considering performance of communication media. Accordingly, communication theories should incorporate the relationship between communication affordances and message content and not merely consider the media as tools for information transmission and processing.

This research may prove useful in helping organizations and individuals better understand the influence of situational and individual factors on creative thinking in group-based problem solving. An important practical implication of the study is that leaders and facilitators of virtual groups should consider both communication media affordances and individual factors when designing group work. As use of a single communication medium will likely not lead to ideal performance (Dennis et al., 2008), both group composition and software selection and configurations should be based on the desired outcome of various phases of group work (e.g., divergent or convergent processes). It further implies that software configurations should not be independent of attitudes toward idea generation and cognitive styles of the group members.

\section{Limitations and Directions for Future Research}

Some limitations of the study and directions for future research should be pointed out. First, the degree to which the findings can be regarded as valid for other people and in other settings (i.e., external validity) must always be accorded special attention. In this case, the use of collaborative tools for group discussions had to be controlled, and the participants' abilities to communicate were therefore restrained. Consequently, the communication may have felt unnatural for some. This was necessary, however, in order to manipulate the communication affordances in the desired way and to ensure internal validity. 
Another limitation of the study was the length of the experiment. Given the relatively high complexity of the task, a longer time frame might have been desirable. Future research should therefore apply a more longitudinal design and at the same time control the communication means during the whole experimental period. The group sizes applied in the experiment may also have constituted a limitation. Group sizes of 3, 4, and 5 were used, which are common in many CMCbased problem-solving experiments. However, studies of the effects of media affordances on group dynamics in large CMC-supported groups are important (Lowry et al., 2009), and analyzing the effects of communication affordances in different-sized groups is therefore a direction future research could take.

Finally, from a wider perspective, an interesting and important issue for future research is how the findings correspond to performance measures (i.e., the quality and success of products and services that are developed). Further, as complete models of problem-solving activities involve ideative and evaluative thinking and behavior in several phases of the total problem-solving process, it is important to investigate the effects of communication affordances within each phase of the process. Basadur (1995a) found that the degree to which a person might accept and practice ideation and evaluation depends on whether s/he is in the problem-finding phase, the problem solution phase, or the solution implementation phase. The question is, then, how communication affordances influence divergent and convergent thinking processes in these stages.

\section{References}

Ashton-James, C. E., \& Chartrand, T. L. (2009). Social cues for creativity: The impact of behavioral mimicry on convergent and divergent thinking. Journal of Experimental Social Psychology, 45(4), 1036-1040.

Ballard, D. I., \& Seibold, D. R. (2004). Organizational members' communication and temporal experience: Scale development and validation. Communication Research, 31(2), 135-172.

Baron, R. M., \& Kenny, D. A. (1986). The moderator-mediator variable distinction in social psychological research: Conceptual, strategic, and statistical considerations. Journal of Personality and Social Psychology, 51(6), 1173-1182.

Basadur, M. I. N. (1995a). Optimal ideation-evaluation ratios. Creativity Research Journal, 8(1), 63-75.

Basadur, M. I. N. (1995b). The power of innovation: How to make innovation a way of life and put creative solutions to work. London: Pitman Publishing.

Basadur, M. I. N., \& Finkbeiner, C. T. (1985). Measuring preference for ideation in creative problemsolving training. The Journal of Applied Behavioral Science, 21(1), 37-49.

Basadur, M. I. N., Graen, G. B., \& Green, S. G. (1982). Training in creative problem-solving: Effects on ideation and problem finding and solving in an industrial research organization. Organizational Behavior and Human Performance, 30(1), 41-70.

Basadur, M. I. N., Taggar, S., \& Pringle, P. A. M. (1999). Improving the measurement of divergent thinking attitudes in organizations. The Journal of Creative Behavior, 33(2), 75-111.

Blazevic, V., \& Lievens, A. (2004). Learning during the new financial service innovation process: Antecedents and performance effects. Journal of Business Research, 57(4), 374-391.

Brophy, D. R. (1998). Understanding, measuring, and enhancing individual creative problem-solving efforts. Creativity Research Journal, 11(2), 123-150.

Burgoon, J. K., Bonito, J. A., Bengtsson, B., Ramjrez Jr, A., Dunbar, N. E., \& Miczo, N. (1999). Testing the interactivity model: Communication processes, partner assessments, and the quality of collaborative work. Journal of Management Information Systems, 16(3), 33-56.

Burke, K., \& Chidambaram, L. (1999). How much bandwidth is enough? A longitudinal examination of media characteristics and group outcomes. MIS Quarterly, 23(4), 557-579. 
Clark, C. H. (2010). Brainstorming: The dynamic new way to create successful ideas: Kathode Ray Enterprises.

Collaros, P. A., \& Anderson, L. R. (1969). Effect of perceived expertness upon creativity of members of brainstorming groups. Journal of Applied Psychology, 53(2, Pt.1), 159-163.

Connolly, T., Jessup, L. M., \& Valacich, J. S. (1990). Effects of anonymity and evaluative tone on idea generation in computer-mediated groups. Management Science, 36(6), 689-703.

Cropley, A. (2006). In praise of convergent thinking. Creativity Research Journal, 18(3), 391-404.

Daft, R. L., \& Lengel, R. H. (1986). Organizational information requirements, media richness and structural design. Management Science, 32(5), 554-571.

de Leede, J., Kraan, K. O., den Hengst, M., \& van Hooff, M. L. M. (2008). Conditions for innovation behaviour of virtual team members: A 'high-road' for internationally dispersed virtual teams. Journal of eWorking, 2(1), 22-46.

DeLuca, D. (2008). A new model and theory of asynchronous creativity. In N. F. Kock (Ed.), Encyclopedia of e-collaboration. Hershey, PA: IGI Global.

DeLuca, D., \& Valacich, J. S. (2006). Virtual teams in and out of synchronicity. Information Technology \& People, 19(4), 323-344.

Dennis, A. R., Aronson, J. E., Heninger, W. G., \& Walker Ii, E. D. (1999). Structuring time and task in electronic brainstorming. MIS Quarterly, 23(1), 95-108.

Dennis, A. R., Fuller, R. M., \& Valacich, J. S. (2008). Media, tasks, and communication processes: A theory of media synchronicity. MIS Quarterly, 32(3), 575-600.

Dennis, A. R., Fuller, R. M., \& Valacich, J. S. (2009). Media synchronicity and media choice. Choosing media for performance. In T. Hartmann (Ed.), Media choice: A theoretical and empirical overview. New York: Routhledge.

Dennis, A. R., \& Valacich, J. (1999). Rethinking media richness: Towards a theory of media synchronicity. Paper presented at the 32nd Hawaii International Conference on System Sciences, Los Alamitos, CA.

Dennis, A. R., Wixom, B. H., \& Vandenberg, R. J. (2001). Understanding fit and appropriation effects in group support systems via meta-analysis. MIS Quarterly, 25(2), 167-193.

DeSanctis, G., \& Gallupe, R. B. (1987). A foundation for the study of group decision support systems. Management Science, 33(5), 589-609.

Diehl, M., \& Stroebe, W. (1987). Productivity loss in brainstorming groups: Toward the solution of a riddle. Journal of Personality and Social Psychology, 53(3), 497-509.

Garfield, M. J., Taylor, N. J., Dennis, A. R., \& Satzinger, J. W. (2001). Research report: Modifying paradigms-individual differences, creativity techniques, and exposure to ideas in group idea generation. Information Systems Research, 12(3), 322.

Girotra, K., Terwiesch, C., \& Ulrich, K. T. (2010). Idea generation and the quality of the best idea. Management Science, 56(4), 591-605.

Guilford, J. P. (1967). The nature of human intelligence. New York: McGraw-Hill.

Guo, Z., Tan, F. B., \& Cheung, K. (2010). Students' uses and gratifications for using computer-mediated communication media in learning contexts. Communications of AIS, 27(Article 20), 339-378.

Hung, Y.-T. C., Duyen, N., Kong, W.-C., \& Chua, A.-L. (2008). Reexamining media capacity theories using workplace instant messaging. IEEE Transactions on Professional Communication, 51(4), 352368.

Jessup, L. M., Connolly, T., \& Galegher, J. (1990). The effects of anonymity on GDSS group process with an idea-generating task. MIS Quarterly, 14(3), 313-321. 
Kaufmann, G. (1995). A theory of cognitive strategy preferences in problem-solving. In G. Kaufmann, T. Helstrup, \& K. H. Teigen (Eds.), Problem-solving and cognitive processes. A festschrift in honour of Kjell Raaheim. Bergen: Fagbokforlaget.

Kaufmann, G., \& Martinsen, Ø. (1993). The A-E inventory. Revised. Bergen: University of Bergen.

Kock, N. F. (1997). The effects of asynchronous groupware on business process improvements. Unpublished doctoral dissertation, University of Waikato, New Zealand.

Kock, N. F. (2005). Media richness or media naturalness? The evolution of our biological communication apparatus and its influence on our behavior toward E-communication tools. IEEE Transactions on Professional Communication 48(2), 117-130.

Kraemer, K. L., \& King, J. L. (1988). Computer-based systems for cooperative work and group decision making. ACM Computing Surveys, 20(2), 115-127.

Kuo, F.-y., \& Yu, C.-p. (2009). An exploratory study of trust dynamics in work-oriented virtual teams. Journal of Computer-Mediated Communication, 14(4), 823-854.

Litchfield, R. C. (2009). Brainstorming rules as assigned goals: Does brainstorming really improve idea quantity? Motivation and Emotion, 33(1), 25-31.

Lowry, P. B., Romano, N. C., Jenkins, J. L., \& Guthrie, R. W. (2009). The CMC interactivity model: How interactivity enhances communication quality and process satisfaction in lean-media groups. Journal of Management Information Systems, 26(1), 155-195.

Malhotra, A., Majchrzak, A., Carman, R., \& Lott, V. (2001). Radical innovation without collocation: A case study at Boeing-Rocketdyne. MIS Quarterly, 25(2), 229-249.

Martinsen, Ø. (1995). Insight with style: Cognitive style and its function in solving insight problems. In G. Kaufmann, T. Helstrup, \& K. H. Teigen (Eds.), Problem-solving and cognitive processes. A festschrift in honour of Kjell Raaheim. Bergen: Fagbokforlaget.

Muhren, W. J., Van Den Eede, G., \& Van de Walle, B. (2009). Making sense of media synchronicity in humanitarian crises. IEEE Transactions on Professional Communication, 52(4), 377-397.

Murthy, U. S., \& Kerr, D. S. (2003). Decision making performance of interacting groups: an experimental investigation of the effects of task type and communication mode. Information \&amp; Management, 40(5), 351-360.

Münzer, S., \& Borg, A. (2008). Computer-mediated communication: synchronicity and compensatory effort. Applied Cognitive Psychology, 22(5), 663-683.

Münzer, S., \& Holmer, T. (2009). Bridging the gap between media synchronicity and task performance. Effects of media characteristics on process variables and task performance indicators in an information pooling task. Communication Research, 36(1), 76-103.

Nagasundaram, M., \& Dennis, A. R. (1993). When a group is not a group: The cognitive foundation of group idea generation. Small Group Research, 24(4), 463-489.

Niinimäki, T., Piri, A., Lassenius, C., \& Paasivaara, M. (2011). Reflecting the choice and usage of communication tools in global software development projects with media synchronicity theory. Journal of Software Maintenance and Evolution: Research and Practice. doi: 10.1002/smr.566

Nunamaker, J. F., Applegate, L. M., \& Konsynski, B. R. (1988). Computer-aided deliberation: Model management and group decision support. Operations Research, 36(6), 826.

Nunamaker, J. F., Dennis, A. R., Valacich, J. S., \& Vogel, D. R. (1991). Information technology for negotiating groups: Generating options for mutual gain. Management Science, 37(10), 1325-1346.

Nunamaker, J. F., Dennis, A. R., Valacich, J. S., Vogel, D. R., \& George, J. F. (1991). Electronic meeting systems to support group work. Communications of the ACM, 34(7), 40-61.

Parnes, S. J., \& Harding, H. F. (Eds.). (1992). Source book for creative problem solving. New York: Creative Education Foundation. 
Paulus, P. B., \& Dzindolet, M. T. (1993). Social influence processes in group brainstorming. Journal of Personality and Social Psychology, 64(4), 575-586.

Pinsonneault, A., \& Heppel, N. (1997). Anonymity in group support systems research: A new conceptualization, measure, and contingency framework. Journal of Management Information Systems, 14(3), 89-108.

Reinig, B. A., Briggs, R. O., \& Nunamaker, J. F. (2007). On the measurement of ideation quality. Journal of Management Information Systems, 23(4), 143-161.

Shepherd, M. M., Briggs, R. O., Reinig, B. A., Yen, J., \& Nunamaker, J. F. (1995). Invoking social comparison to improve electronic brainstorming: Beyond anonymity. Journal of Management Information Systems, 12(3), 155-170.

Steiner, I. D. (1972). Group processes and productivity. New York: Academic Press.

Valacich, J. S., Dennis, A. R., \& Numamaker, J. F. (1992). Group size and anonymity effects on computermediated idea generation. Small Group Research, 23(1), 49-73.

Valacich, J. S., Jessup, L. M., Dennis, A. R., \& Nunamaker, J. F. (1992). A conceptual framework of anonymity in Group Support Systems. Group Decision and Negotiation, 1(3), 219-241.

Van de Ven, A. H., Polley, D. E., Garud, R., \& Venkataraman, S. (1999). The innovation journey. New York: Oxford University Press.

Wolf, K. M., \& Mieg, H. A. (2010). Cognitive determinants of the success of inventors: Complex problem solving and deliberate use of divergent and convergent thinking. European Journal of Cognitive Psychology, 22(3), 443-462. 


\section{Appendix: \\ List of killer phrases in brainstorming sessions}

- It won't work ...

- We haven't the time...

- We haven't the manpower...

- We've tried that before...

- We're not ready for it yet. .

- All right in theory but can you put it into practice?

- Too academic ...

- What will the customers think?

- Somebody would have suggested it before if it were any good...

- Too modern ...

- Too old-fashioned...

- It's too expensive...

- You don't understand our problem...

- Won't work in our industry ...

- We can't do it under the regulations ...

- Nuts...

- Political dynamite...

- Sounds good but don't think it will work ...

- No regulations covering it. . .

- We've never used that approach before...

- It'll mean more work ...

- It has been the same for twenty years so it must be good ...

- What bubblehead thought that up?

- I just know it won't work ...

- That's not our problem...

- Engineering can't do it. . .

- Won't work...

- Customers won't stand for it. . .

- You'll never sell that to management. . .

- Don't move too fast. . .

- Let's wait and see...

- The union will scream ...

- Here we go again...

- I don't see the connection ... .

- It's not our responsibility ...

- Yes, but...

- It's too early ...

- It's too late...

- $\quad$ It will offend ...

- It won't pan out ...

- You don't understand the problem ...

- It's not in the manual. . .

- All right in theory...

(from from Clark (2010) and Basadur (1995b)). 


\section{Biography}

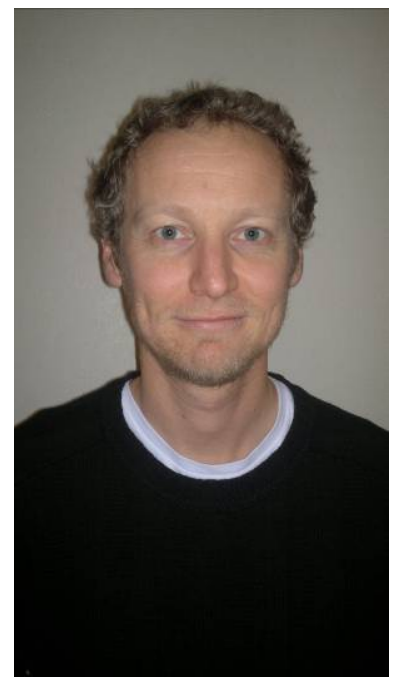

Leif Jarle Gressgård is a Senior Researcher at International Research Institute of Stavanger (IRIS) in Bergen, Norway. He holds a Ph.D. in Information Management from the Norwegian School of Economics. His primary research interests are in the fields of computer-mediated communication, innovation and creativity management, automation systems and decision support, and organizational learning and safety. 